\title{
The Effect of Biophilic Design Patterns on Employee's Health and Well-being: A Systematic Review
}

\author{
Farin Khanehshenas ${ }^{1}$ (D), Peymaneh Habibi ${ }^{1}$, Seyed Abolfazl Zakerian ${ }^{2 *}$ iD
}

1. PhD Student, Department of Occupational Health Engineering, School of Public Health, Tehran University of Medical Sciences, Tehran, Iran

2. Associated Professor, Department of Occupational Health Engineering, School of Public Health, Tehran University of Medical Sciences, Tehran, Iran

\section{Article Info}

Received: 2020/01/17;

Accepted: 2020/01/29;

ePublished: 2020/02/29

10.30699/jergon.7.4.1

Use your device to scan and read the article online

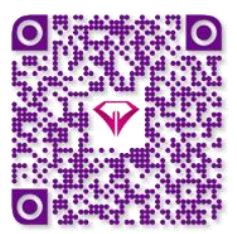

Corresponding Author Seyed Abolfazl Zakerian Department of Occupational Health Engineering, School of Public Health, Tehran

University of Medical Sciences,

Tehran, Iran

Tel: 09125910655

Email: zakerian@tums.ac.ir

Copyright (C) 2020, This is an original open-access article distributed under the terms of the Creative Commons Attribution-noncommercial 4.0 International License which permits copy and redistribute of the material just in noncommercial usages with proper citation.

\section{How to Cite This Article:}

Khanehshenas F, Habibi P, Zakerian S A. The Effect of Biophilic Design Patterns on Employee's Health and Wellbeing: A Systematic Review. Iran J Ergon. 2020; 7 (4): 1-11
Background and Objectives: Ergonomics is associated with the study and systematic design of the workplace to improve human health and well-being. The health and well-being of employees are influenced by a variety of factors. Nature is a new paradigm in occupational ergonomics that has not been well explored in the main texts of ergonomics in relation to human well-being. Therefore, the main purpose of this study was to investigate the results of joining with nature on staff health, especially well-being in the form of a systematic review study.

Methods: By searching articles published from 2000 to 2019 in the field of Biophilic design, 25 articles were selected for the present systematic study based on the research criteria. Non-English language articles were excluded.

Results: The results of this study showed that Biophilic design is associated with improved human well-being, performance, concentration and stress reduction.

Conclusion: Organizations, with the help of ergonomists, should consider such changes in the workplace, and nature-based solutions as strategic programs for improving well-being rather than merely applying a temporary strategy that changes the physical condition of a building or its landscape.

Keywords: Ergonomics, Biophilic design, Well-being, Workplace, Nature 


\section{تاثير الكوهاى طراحى بيوفيليك بر سلامتى و رفاه كاركنان: مرور سيستماتيك}

\section{فرين خانهشناس (iD) ، ييمانه حبيبى'، سيد ابوالفضل ذاكريان}

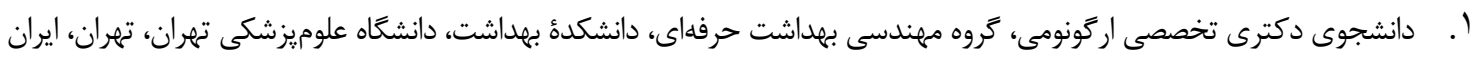



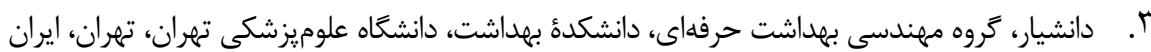

\begin{tabular}{|c|c|}
\hline خلاصد & اطلاعات مقاله \\
\hline 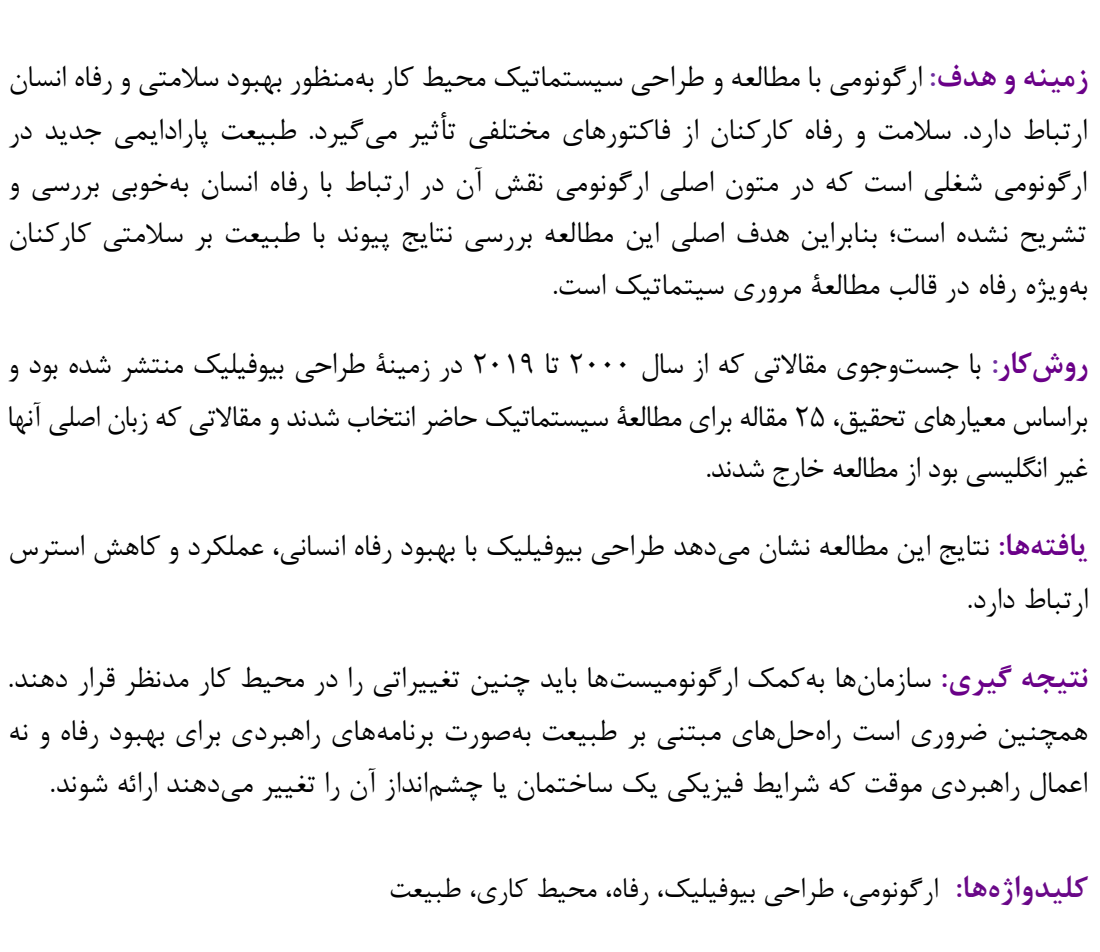 & 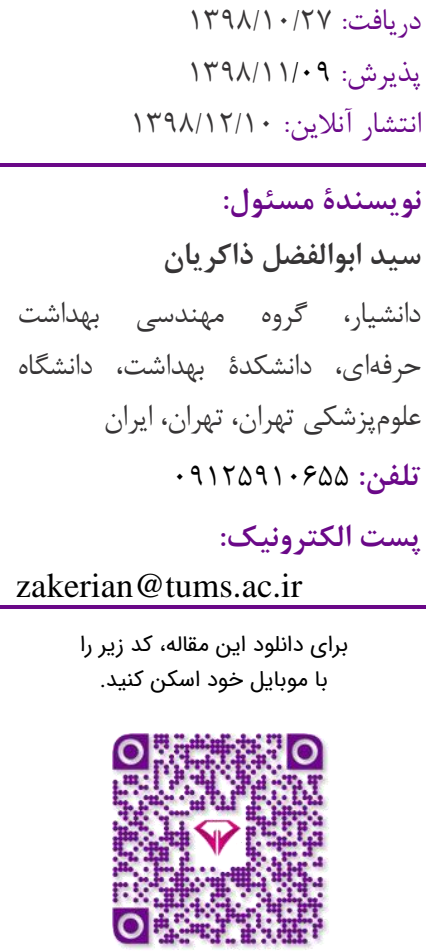 \\
\hline
\end{tabular}

مقد مه

محيط كار با هدف ارتقاى سلامت و رفاه انسان مدنظر قرار بخيرد

"بيوفيليا" (Biophilia) بركرفته از كلمهاى يونانى به معناى

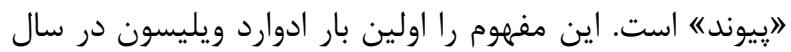

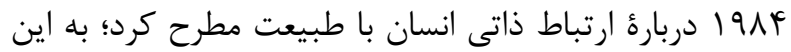
معنا كه انسان از نظر بيولوزيكى به طبيعت وابسته است [ب].

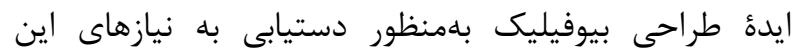

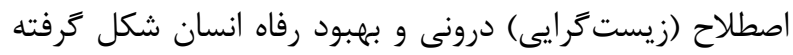

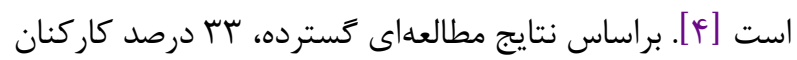
اذعان دارند كه طراحى دفاتر ادارى بر تصميمَّيرى آنها
Chartered ) انجمن ارگونومى و عوامل انسانى خبره (Institute of Ergonomics and Human Factors ץ ا • ب بر ارتقاى سلامت و رفاه (Well-being) انسان در محيط كار با به كارگيرى دانش ارگونومى تأكيد كرده است [1 ]. از آنجا

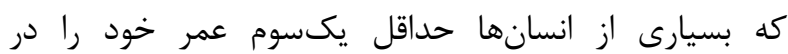

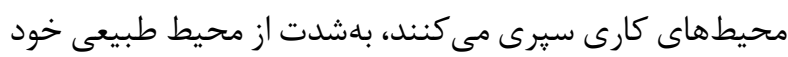

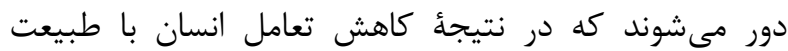
مشكلاتى براى انسان به وجود مى آيد؛ بنابر اين بايد پييوند انسان

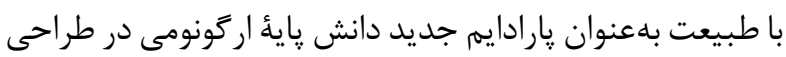




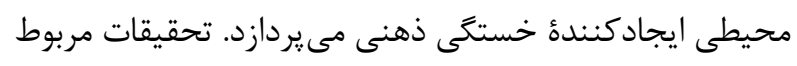



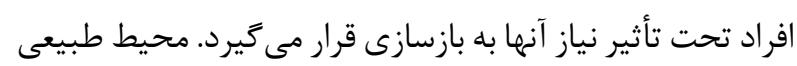



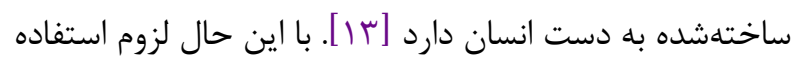

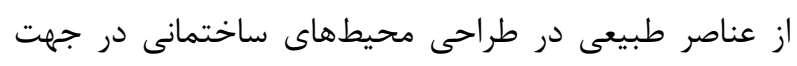

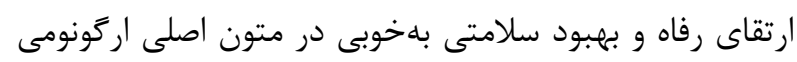

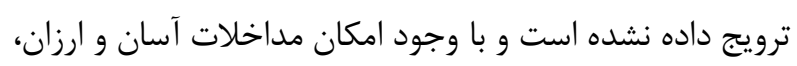
بيشتر اقدامات به رويكردهاى سنتى از قبيل برنامههاى ورزشى دادي

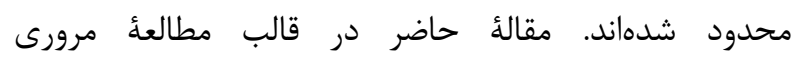

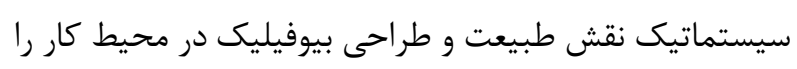

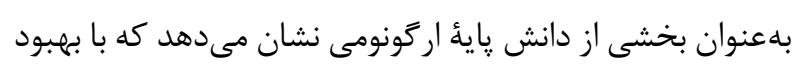
سلامت روانى و رفاه انسان ارتباط دارد.

\section{روش كار}

همؤ مقالات مرتبط با موضوعات طراحى بيوفيليك و

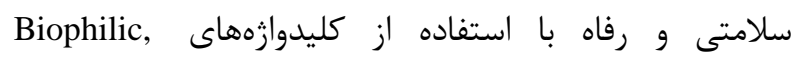
Health Performance, Well-being, Nature و اطلاعاتى Scopus, PubMed, Google scholar, Medline Science Direct

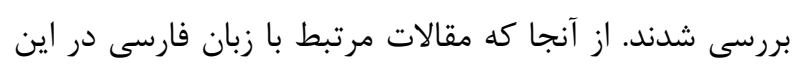



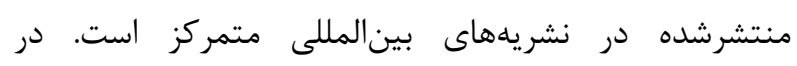



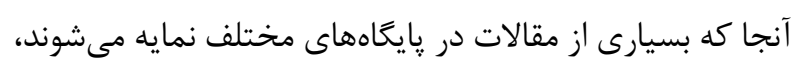

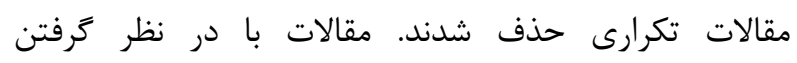
شاخصهايى مانند اختصاصداشتن به حداقل يكى ازل از ابعاد مختلف سلامتى (اعم از سلامت ذهنى و فيزيكى) و رفاه انسانى



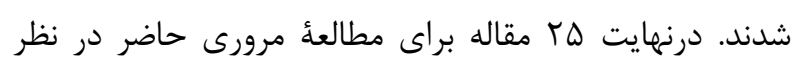



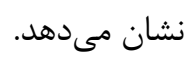

يافتهها



رنت اولين مؤلفهُ مورد توجه در طراحى است، اما تحقيقات كمى در ارتباط با بررسى تأثيرات اين مؤلفه بر عامل
تأثير كذار است. QV درصد از وجود عناصر سبز از قبيل كياهان

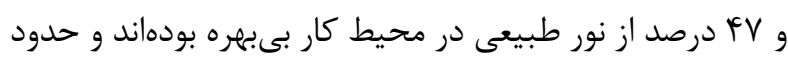

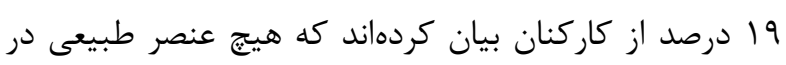

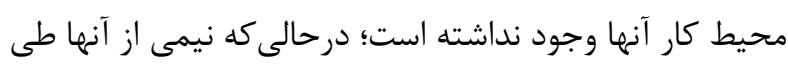

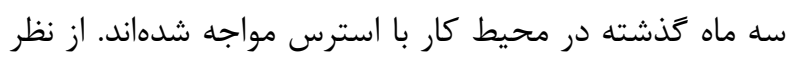
VV

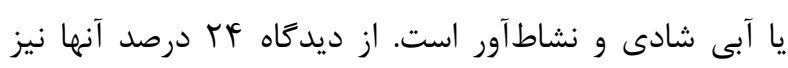

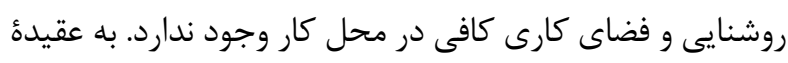

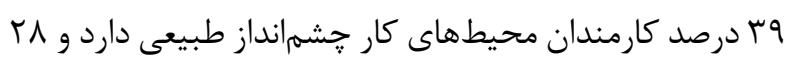

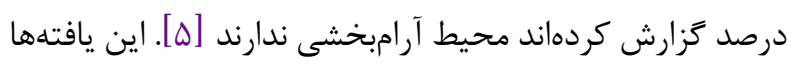

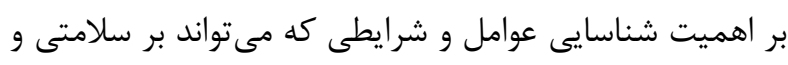

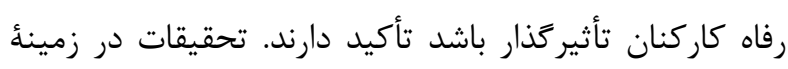

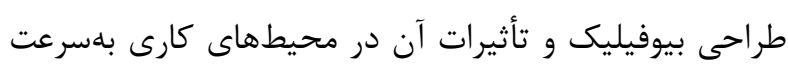

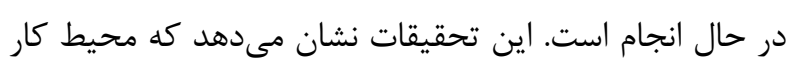

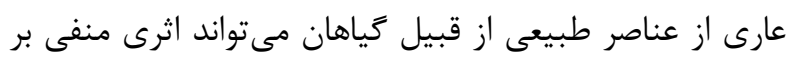

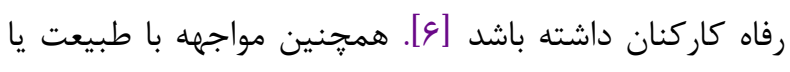
ترسيمى از آن در محيط كار سبب كاهش استرس و افسردكى بانى


و رفاه كاركنان مىشود [V]

\section{وابستكى انسان به طبيعت و ديدكاههاى نظرى}

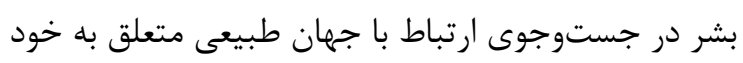

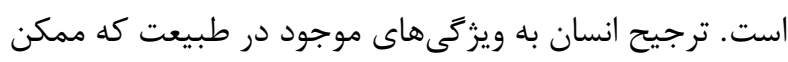

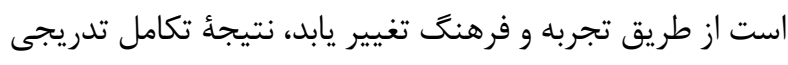

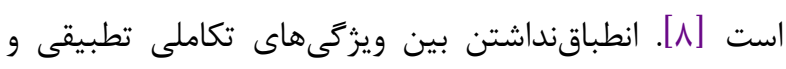
محيطزيست مدرن به بروز ناساز

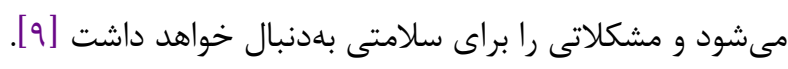

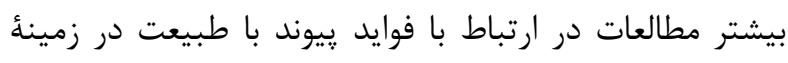

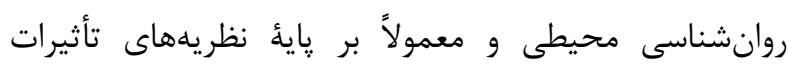

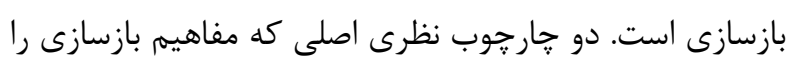

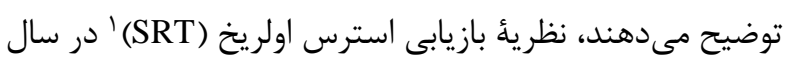

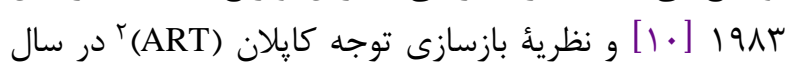

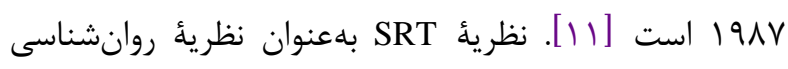





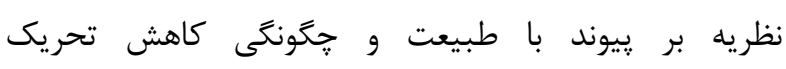

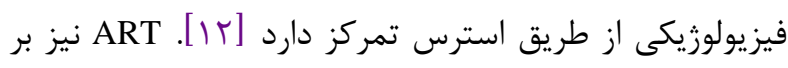

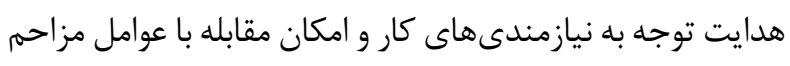


دو مطالعه از ها مطالعة انتخابشده، به بررسى تأثيران حضور گَياهان در محيط كار بر عامل انسانى يرداختهاند كه نتايج آنها در جدول ب آمده است. براساس اين مطالعات، كاركنان

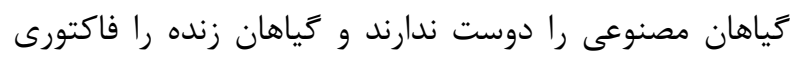

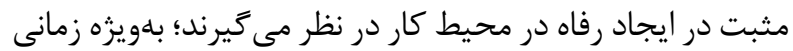

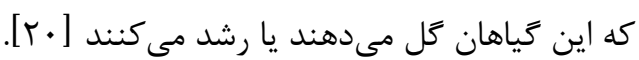

\section{جشم/اندازهاى طبيعى در محيط كار}

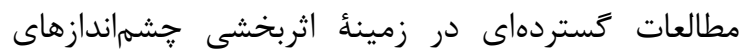
طبيعى و نمونهايى از طبيعت بر عامل انسانى انجام شده است. از مجموع ه T مطالعهُ بررسىشده IV مطالعه به اين موضوع اختصاص داشت كه نتايج آنها در جدول ع آ آمده است.
انسانى وجود دارد. سه مطالعه از ل r مطالعه به اين موضوع يرداختهاند. در جدول ا نتايج اين بررسى آمده است كه


طبيعت در محيط كار است.

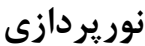

از هr مطالعهُ بررسى شده دو مورد به بررسى تأثيرات مواجهه

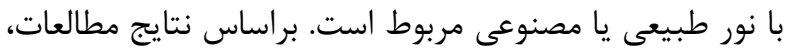

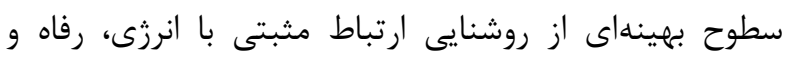

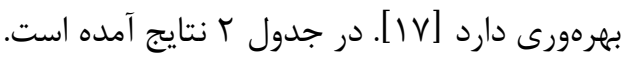
كياهان

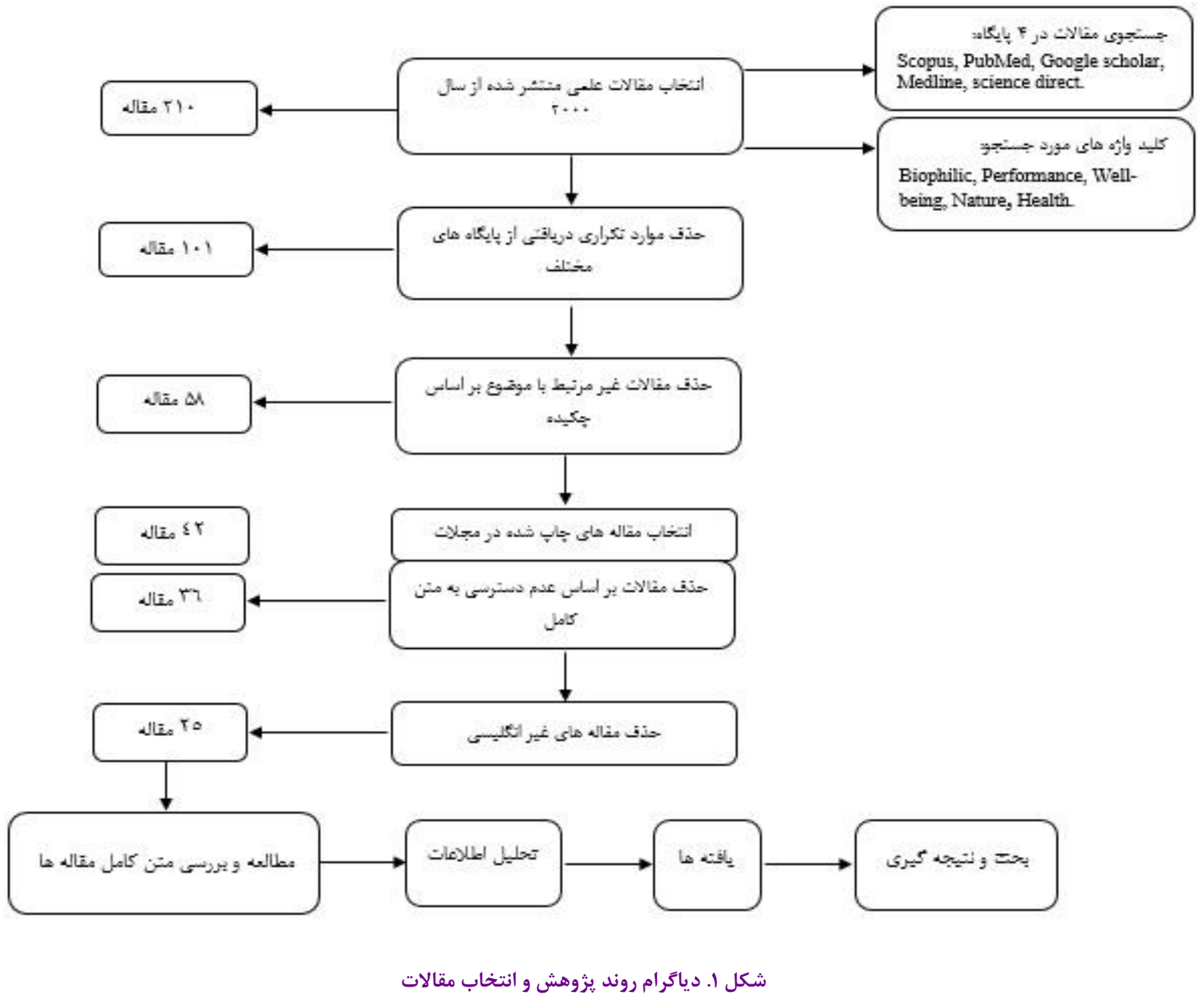


جدول ا. جدول ا. مقالات منتشر شده در زمينه تاثير رنََ بر سلامتى و رفاه

\begin{tabular}{|c|c|c|c|c|c|}
\hline نتيجة مطالعه & موضوع مطالعd & طراحى مطالعه & تعداد نمونه & نويسندة اول و سال مطالعه & رديف \\
\hline خاهدة رنح سبز سبب افزايش عملكرد & تأثير رنغ سبز بر خلاقيت & تجربى & وع نفر & $\begin{array}{c}\text { Lichtenfeld, } 2012 \\
{[14]}\end{array}$ & 1 \\
\hline  & 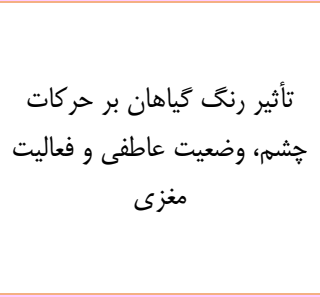 & تجربى & r r دانشجو & Sadek, 2013 [15] & $r$ \\
\hline 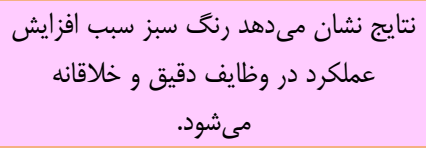 & تأثير رنح بر عملكرد شناختى و & مقطعى & و و نفر & Mehta, 2009 [16] & $r$ \\
\hline
\end{tabular}

جدول r: مقالات منتشرشده در زمينهُ تأثير نور بر سلامتى و رفاه

\begin{tabular}{|c|c|c|c|c|c|}
\hline نتيجة مطالعه & موضوع مطالعه & طراحى مطالعه & تعداد شر كت كنندكان & نويسندة اول و سال مطالعd & رديف \\
\hline 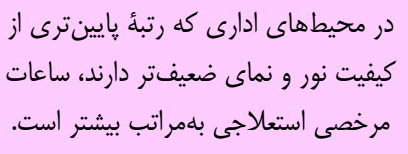 & $\begin{array}{c}\text { كأثيرات نور روز بر سلامتى و } \text { كاعات مرخصى } \\
\text { كاركنان }\end{array}$ & مقطعى & V Sارمند IVD & Elzeyadi, 2012 [18] & 1 \\
\hline 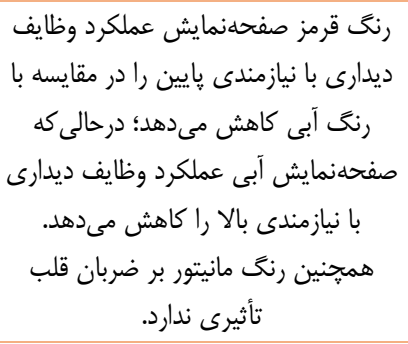 & 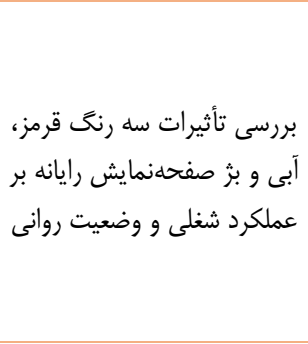 & مقطعى & 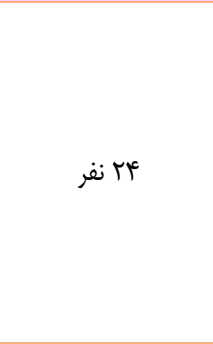 & Hatta, 2002 [19] & $r$ \\
\hline
\end{tabular}

جدول ץ. مقالات منتشرشده در زمينهُ تأثير گياهان بر سلامتى و رفاه

\begin{tabular}{|c|c|c|c|c|c|}
\hline نتيجة مطالعه & موضوع مطالعه & طراحى مطالعه & تعداد نمونه & نويسندة اول و سال مطالعه & رديف \\
\hline 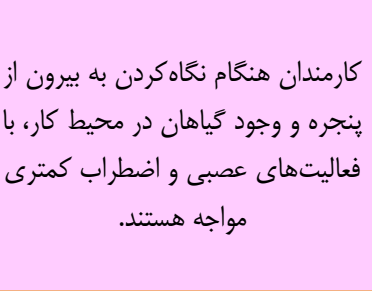 &  & تجربى & مب نفر & Chang, 2005 [2] & 1 \\
\hline 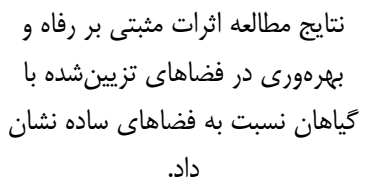 & 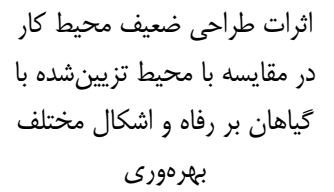 & مقطعى & rال & Knight, 2010 [21] & $r$ \\
\hline
\end{tabular}




\begin{tabular}{|c|c|c|c|c|c|}
\hline نتيجهُ مطالعه & موضوع مطالعه & طراحى مطالعه بر سلامت & 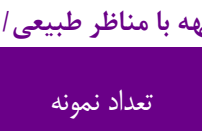 & لات منتشرشده در زمينهُ تأثير مواج & 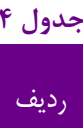 \\
\hline 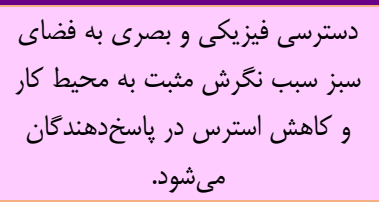 &  & مقطعى & وسזץ نفر & Lottrup, 2013 [22] & 1 \\
\hline 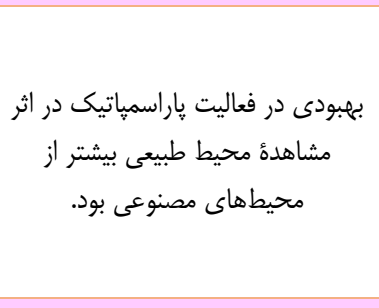 &  & 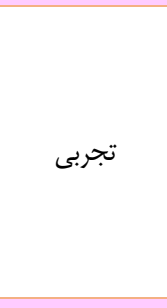 & 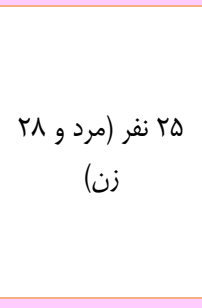 & Brown, 2013 [23] & $r$ \\
\hline 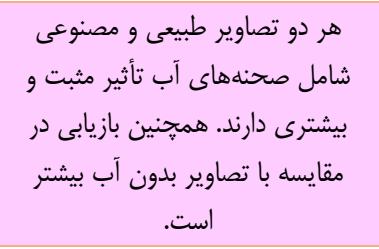 & بررسى تأثير تصاوير مربوط به بآب بازيى توجه & مقطعى & مناظر طبيعى و از تصوير از & White, 2010 [24] & r \\
\hline 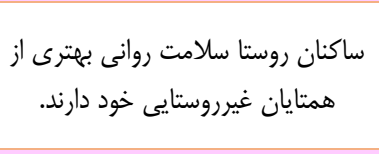 & 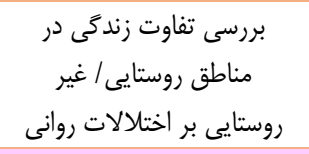 & مقطعى & نف V\&Dq & Weich , 2003 [25] & $\varepsilon$ \\
\hline  &  & ر إرسيون & 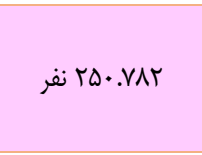 & Maas, 2006 [26] & 0 \\
\hline كيفيت بالاى فضاى سبز با فشارخون & 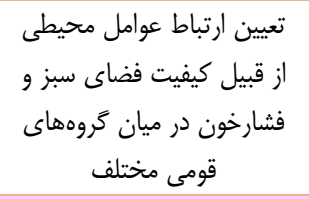 &  & 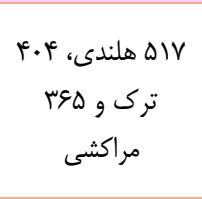 & Agyemang, 2007 [27] & 7 \\
\hline  & بروسى وجود فضاى سبز بر استرسزادر & ر إرسيون & Frarq نفر & Van Den Berg, 2010 [28] & $\checkmark$ \\
\hline 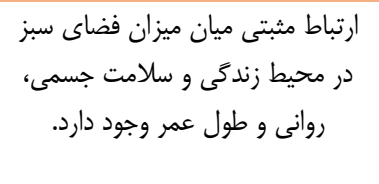 & محيط زندىى بأثيرات فضاى سبز درت، رفاه & مقطعى & - & Groenewegen, 2006 [29] & $\Lambda$ \\
\hline 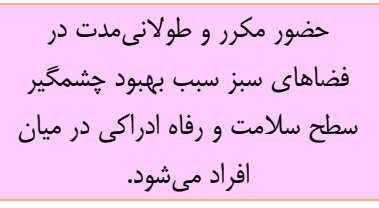 & عامت مؤثر بر ارتقاى & مقطعى & 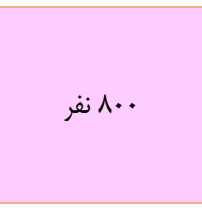 & Lafortezza, 2009 [30] & 9 \\
\hline 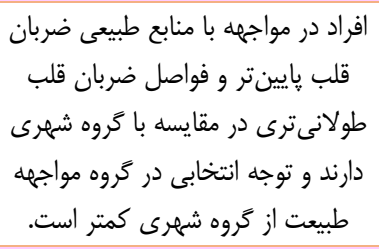 & 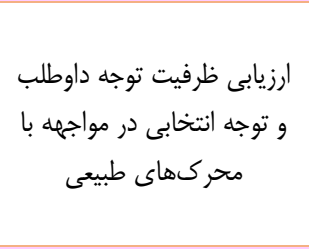 & مقطعى & مץ نفر & Laumann, 2003 [31] & $1+$ \\
\hline بمرات فرسودىى كاهش و توانايى كار & 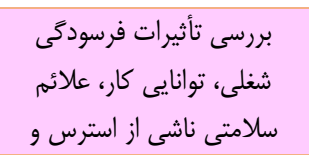 & مقطعى & 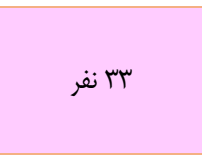 & Sahlin, 2014 [32] & 11 \\
\hline
\end{tabular}




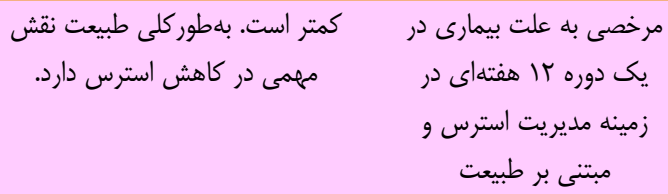

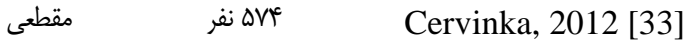

it

\begin{tabular}{|c|c|c|c|c|c|}
\hline ارتباط معنى دارى ميان رابطؤ طبيعت و & بررسى ارتباط طبيعت، رفاه و دواس در ميان & مقطعى مقى & نف FAT.TVD & Howell, 2011 [34] & سו \\
\hline
\end{tabular}

\section{ارتباط معنى دارى ميان مواجهه با}

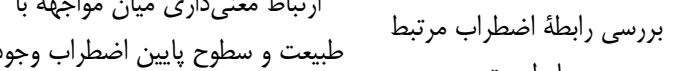
دارد.

$$
\text { با طبيعت }
$$

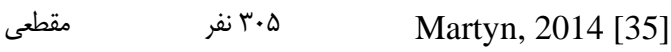

$1 \varepsilon$

\begin{tabular}{|c|c|c|c|c|c|}
\hline رفاه و سلاط مثتى ميان مواجهه با روانى افر اد وجيعت دارد. & 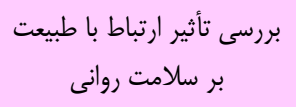 & مقطعى & ا و النفر & Kamitsis, 2013 [36] & 10 \\
\hline 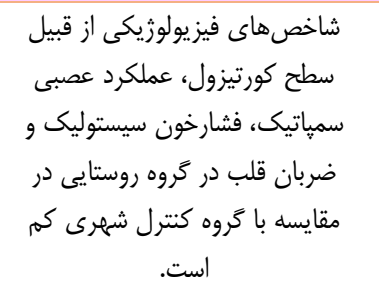 & فيزيولوزيكى روستاييان دمر & مداخلهاى &  & Miyazaki, 2011 [37] & 17 \\
\hline  & 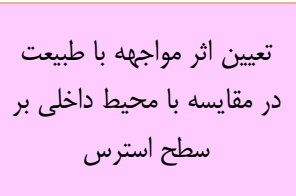 & مداخلهاى & ها 1المند & Ottosson, 2005 [38] & IV \\
\hline
\end{tabular}

بهعنوان عاملى مثبت در حواسيرتى، فرد را به وقفه در كار و صداهاى طبيعت در محيط كار استراحت تشويق مى كند (جدول ه) [rاس]. از ميان مطالعات بررسىشده يك مطالعه با بررسى صداى



جدول ه. مقايسُٔ وضعيت شيب سرسره با استانداردهاى كميسيون ايمنى محصولات آمريكا

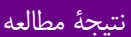
موضوع مطالعه نوع مطالعه


نويسندة اول و سال مطالعه

تأثير مواجها با صداى يرنده و مواجهه با صداهاى طبيعى تأثيرات

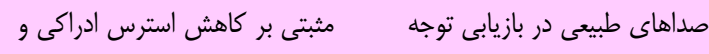

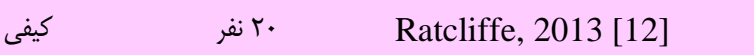
بازيابى توجه افراد دارد. و استرس ادراكى كاركنان

زنان واكنش متفاوتى به رنغ دارند؛ زيرا زنان به تأثيرات

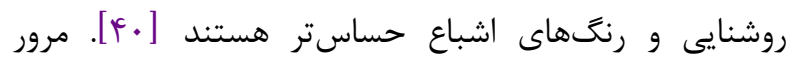
مطالعات نشان مىدهد هيج توافقى در مناسبترين رنگ براى رون محيط داخلى وجود ندارد. بهطور كلى رنى مناسب براى محيط مهيط
به نظر مىرسد مؤلفهُ رنغ تأثيرات تحميلى، احساسى و

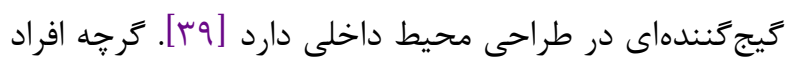
رنت ها را بهطور مشابه درك مى كنند، ترجيحات آنها ميان كشور و فرهنگها متفاوت است. همجنين به نظر مىرسد مردان و 
افزايش سطح ملاتونين، خوابآلودگى و افسردگى مىشود



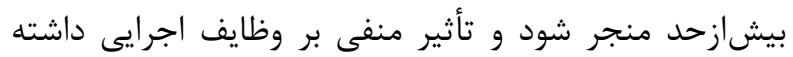



\section{كياهان}

كياهان با ويزگىهاى نامرئى از قبيل رايحه مطبوع،

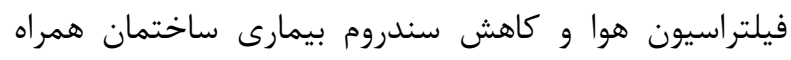

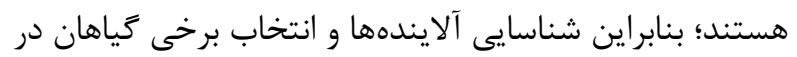

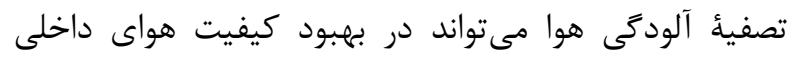

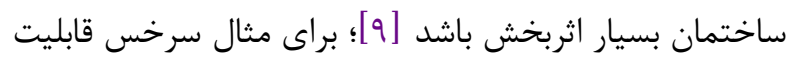


عملكرد دقيق كياهان در بهبود كيفيت داخلى هواي محيط كاردار

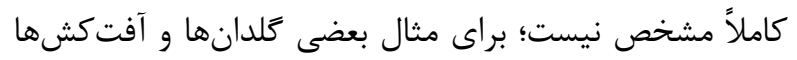

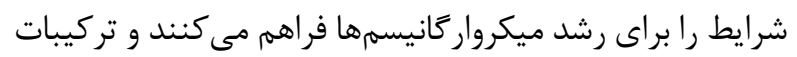


شرايط نامطلوب آنها مكن است بر احساسات و رفاه كاركنان

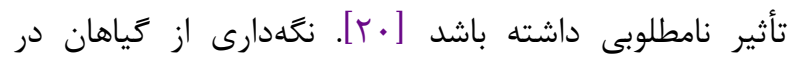
محيطهاى كارى براى كمك به حفظ آرامش و فراهمكردن امكان استراحت، توقف كار و ايجاد تعادل ميان حجم كار روانى



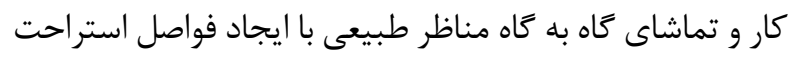



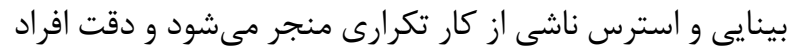

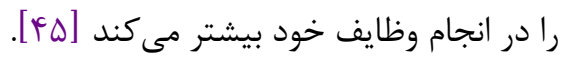

\section{مناظر طبيعى و مصنوعى}

ايجاد جشماندازهاى طبيعى ارزانقيمت مصنوعى است و اثربخشى

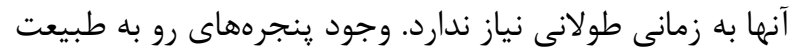

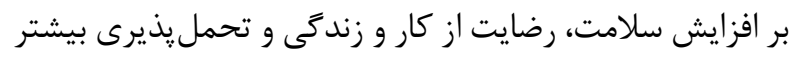

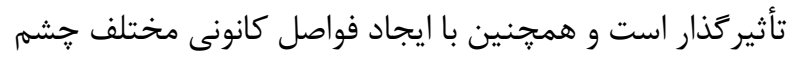





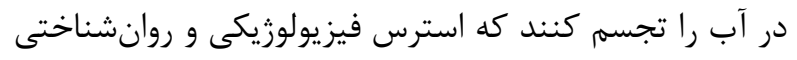

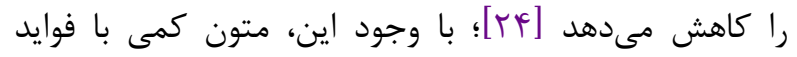

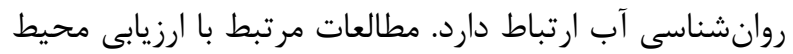

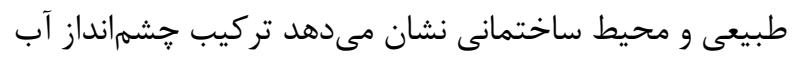

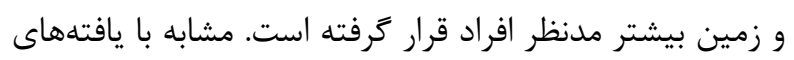



داخلى ادارى رنگ سفيد، بز يا خنثى است [أf]. همجنين

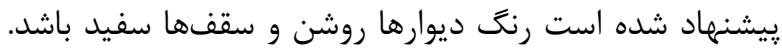

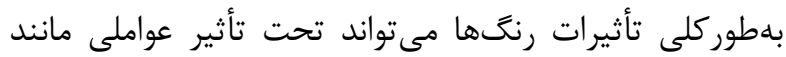

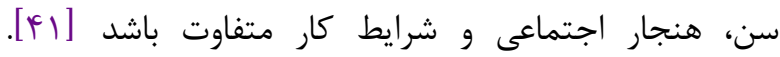
درحالى كه رنخ اولين مؤلفهٔ مدنظر در ورود به طراحى فضاست،



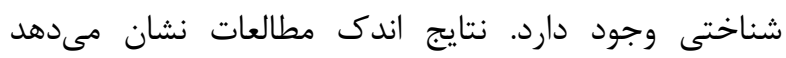
كاركنان به محيطى تمايل دارند كه خلاقيت آنها را تحريك كند.






كارى همراه با خلاقيت، نغاهى كوتاه به رنخ سبز داشته باشند، بيشتر از زمانى كه به رنغ سفيد، خاكسترى يا ديخر رنخدهاى

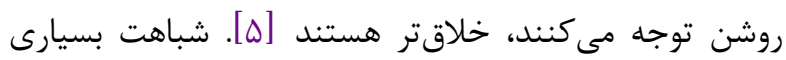

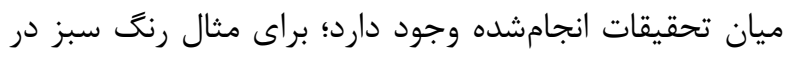

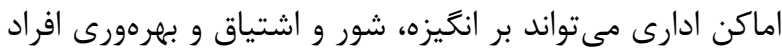

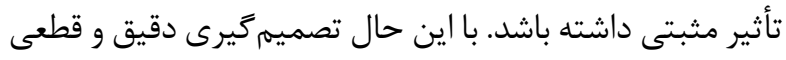

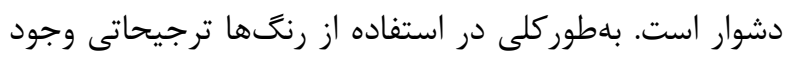

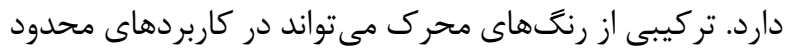

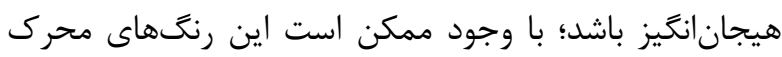

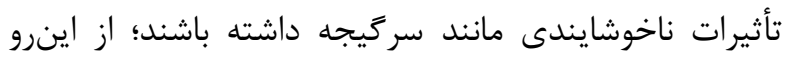
استفاده حداقل از تركيب رنغ أنهاى محرك براى حفظ محيط

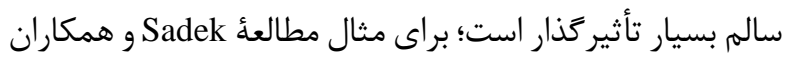

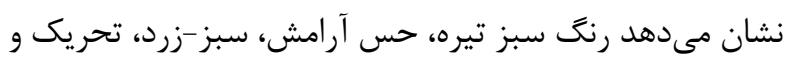

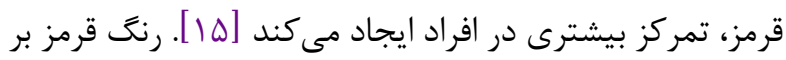
افزايش عملكرد شغلى در وظايفى كه نيازمند تمركز شناختى

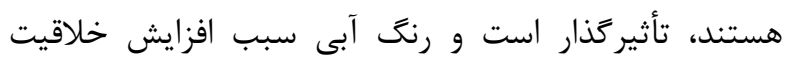

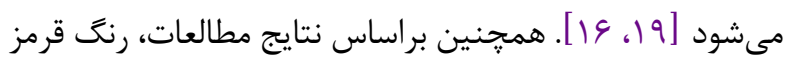
ياسخهاى فيزيولوزيكى قوى ترى ايجاد مى كند؛ براى مثال سبب


رنغ آبى واكنشى متقابل دارد [FY]

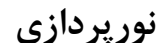

نوريردازى مناسب براى ايجاد عملكرد موفق، ايمن، حس داري آسايش و لذت از فضاى داخلى ضرورى است. نتايج مطالعات إناد

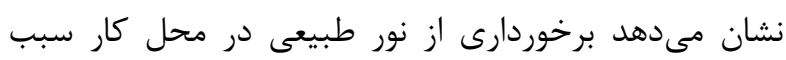

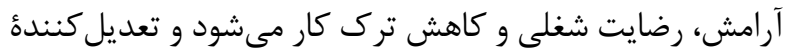

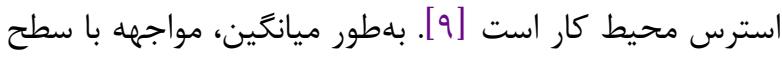

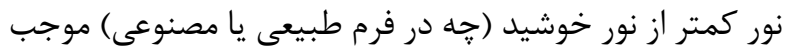




$$
\text { نتيجه }
$$

بخش عمدهاى از مطالعات آزمايشكاهى و ميدانى به بررسى

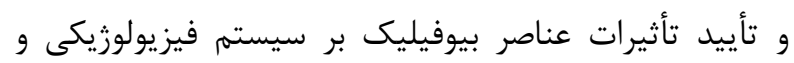











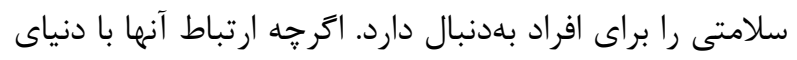

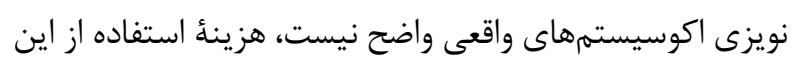

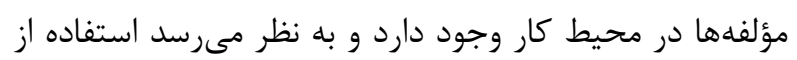



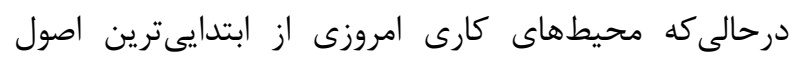

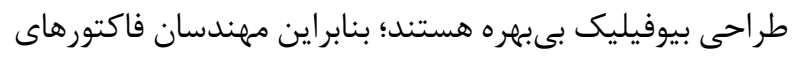

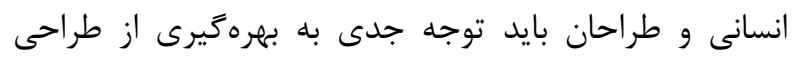

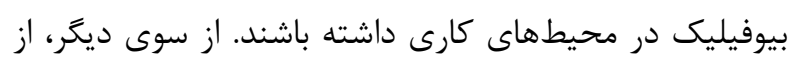

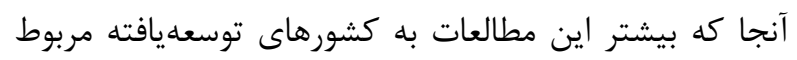

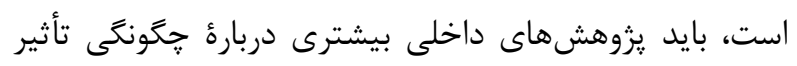

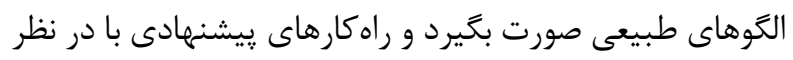



\section{تقدير و تشكر}

نويسندكان از تمامى كسانى كه آنها را در نوشتن اين مقاله يارى رساندند، كمال تشكر و قدردانى را دارند.

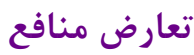

بين نويسندًان هيجَّونه تعارضى در منافع وجود ندارد.

$$
\text { منابع مالى }
$$

منابع مالى اين مطالعه توسط نويسندكان تامين شده است.

\section{References}

1. Chartered Institute of Ergonomics and Human Factors. Royal Charter http://iehforg/ehf/wpcontent/uploads/2013/04/CIEHF-Charterdocumentspdf. 2014.
ادراكى تأثيركذار است. آب تميز نيروبخشتر از آبهاى تيره يا

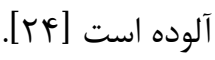

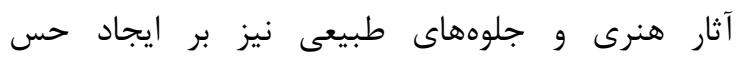

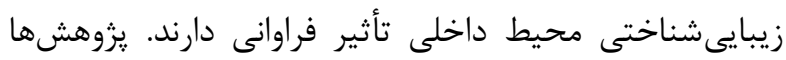



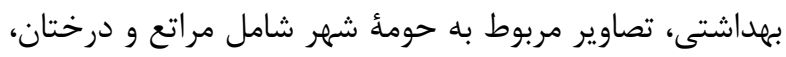







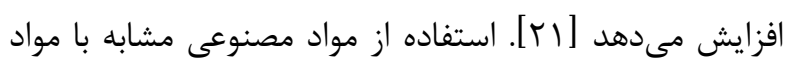



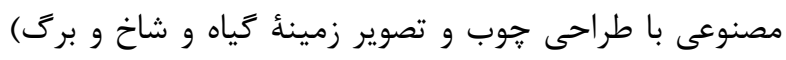

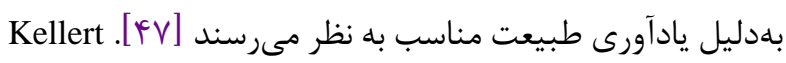

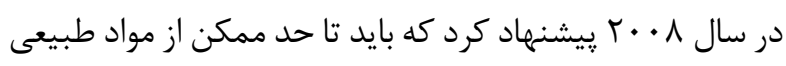

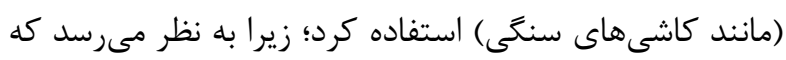



\section{صدا}

صدا هميشه وجود دارد و تأثير مستقيمى بر آسايش، ايمنى صمات

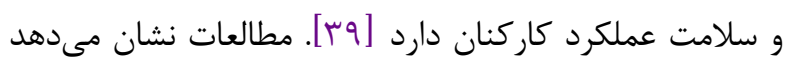

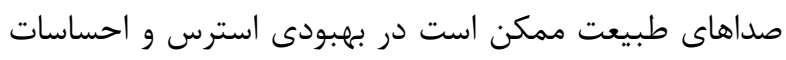

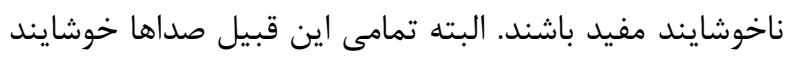

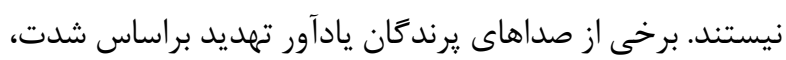

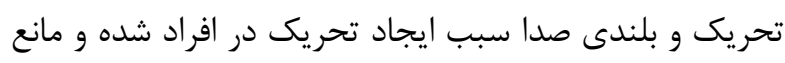

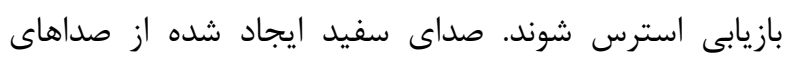

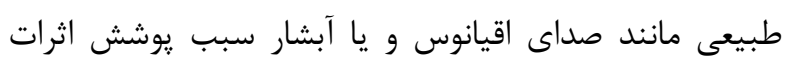

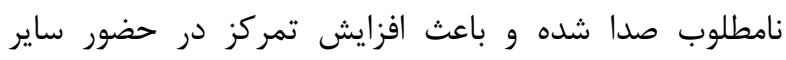







2. Chang CY, Chen PK. Human response to window views and indoor plants in the workplace. HortScience. 2005 Aug $1 ; 40(5): 1354-9$. [DOI:10.21273/HORTSCI.40.5.1354]

3. Wilson EO. Biophillia: The human bond with other species. 
4. Kellert SR. Dimensions, elements, and attributes of biophilic design. Biophilic design: the theory, science, and practice of bringing buildings to life. 2008:3-19.

5. Spaces H. The Global Impact of Biophilic Design in the Workplace, 2015.

6. Grinde B, Patil GG. Biophilia: does visual contact with nature impact on health and well-being? International journal of environmental research and public health. 2009 Sep;6(9):2332-43. [DOI:10.3390/ijerph6092332] [PMID] [PMCID]

7. Richardson M, Maspero M, Golightly D, Sheffield D, Staples V, Lumber R. Nature: A new paradigm for wellbeing and ergonomics. Ergonomics. 2017 Feb 1;60(2):292-305 [DOI:10.1080/00140139.2016.1157213] [PMID]

8. Gullone E. The biophilia hypothesis and life in the 21st century: increasing mental health or increasing pathology?. Journal of happiness studies. 2000 Sep 1;1(3):293-322. [DOI:10.1023/A:1010043827986]

9. Fitzgerald CJ, Danner KM. Evolution in the office: How evolutionary psychology can increase employee health, happiness, and productivity. Evolutionary Psychology. 2012 Dec 20;10(5):147470491201000502. [DOI:10.1177/147470491201000502]

10. Ulrich RS. Aesthetic and affective response to natural environment. InBehavior and the natural environment 1983 (pp. 85-125). Springer, Boston, MA. [DOI:10.1007/978-1-4613-3539-9_4]

11. Kaplan S. Aesthetics, affect, and cognition: Environmental preference from an evolutionary perspective. Environment and behavior. 1987 Jan;19(1):3-2. [DOI:10.1177/0013916587191001]

12. Ratcliffe E, Gatersleben B, Sowden PT. Bird sounds and their contributions to perceived attention restoration and stress recovery. Journal of Environmental Psychology. 2013 Dec 1;36:221-8. [DOI:10.1016/j.jenvp.2013.08.004]

13. Berto R. The role of nature in coping with psychophysiological stress: a literature review on restorativeness. Behavioral sciences. 2014 Dec;4(4):394-409. [DOI:10.3390/bs4040394] [PMID] [PMCID]

14. Lichtenfeld S, Elliot AJ, Maier MA, Pekrun R. Fertile green: Green facilitates creative performance. Personality and Social Psychology Bulletin. 2012 Jun;38(6):784-97. [DOI:10.1177/0146167212436611] [PMID]

15. Sadek ME, Sayaka S, Fujii E, Koriesh E, Moghazy E, El Fatah Y. Human emotional and psychophysiological responses to plant color stimuli. J. Food Agric. Environ. 2013 Jul;11:1584-91.

16. Mehta R, Zhu RJ. Blue or red? Exploring the effect of color on cognitive task performances. Science. 2009 Feb [DOI:10.1126/science.1169144] [PMID] 27;323(5918):1226-9.

17. Edwards L, Torcellini P. Literature review of the effects of natural light on building occupants. National
Renewable Energy Lab., Golden, CO.(US); 2002 Jul 1. [DOI:10.2172/15000841]

18. Elzeyadi I. Daylighting-bias and biophilia: quantifying the impact of daylighting on occupants health. US Green Building Council. http://www. usgbc. org/sites/default/files/OR10_Daylighting\% 20Bias\% 20and\% 20Biophilia. pdf. 2011.

19. Hatta T, Yoshida H, Kawakami A, Okamoto M. Color of computer display frame in work performance, mood, and physiological response. Perceptual and motor skills. 2002 [DOI:10.2466/pms.2002.94.1.39] [PMID] Feb;94(1):39-46.

20. Thomsen JD, Sønderstrup-Andersen HK, Müller R. People-plant relationships in an office workplace: perceived benefits for the workplace and employees. HortScience. 2011 May 1;46(5):744-52. [DOI:10.21273/HORTSCI.46.5.744]

21. Knight C, Haslam SA. The relative merits of lean, enriched, and empowered offices: An experimental examination of the impact of workspace management strategies on well-being and productivity. Journal of Experimental Psychology: Applied. 2010 Jun;16(2):158. [DOI:10.1037/a0019292] [PMID]

22. Lottrup L, Grahn P, Stigsdotter UK. Workplace greenery and perceived level of stress: Benefits of access to a green outdoor environment at the workplace. Landscape and Urban Planning. 2013 Feb 1;110:5-11. [DOI:10.1016/j.landurbplan.2012.09.002]

23. Brown DK, Barton JL, Gladwell VF. Viewing nature scenes positively affects recovery of autonomic function following acute-mental stress. Environmental science \& technology. 2013 Jun 4;47(11):5562-9. [DOI:10.1021/es305019p] [PMID] [PMCID]

24. White M, Smith A, Humphryes K, Pahl S, Snelling D, Depledge M. Blue space: The importance of water for preference, affect, and restorativeness ratings of natural and built scenes. Journal of Environmental Psychology. 2010 Dec 1;30(4):482-93. [DOI:10.1016/j.jenvp.2010.04.004]

25. Weich S, Twigg LI, Lewis G. Rural/non-rural differences in rates of common mental disorders in Britain: prospective multilevel cohort study. The British Journal of Psychiatry. 2006 Jan;188(1):51-7. [DOI:10.1192/bjp.bp.105.008714] [PMID]

26. Maas J, Verheij RA, Groenewegen PP, De Vries S, Spreeuwenberg P. Green space, urbanity, and health: how strong is the relation?. Journal of Epidemiology \& Community Health. 2006 Jul 1;60(7):587-92. [DOI:10.1136/jech.2005.043125] [PMID] [PMCID]

27. Agyemang C, van Hooijdonk C, Wendel-Vos W, UjcicVoortman JK, Lindeman E, Stronks K, Droomers M. Ethnic differences in the effect of environmental stressors on blood pressure and hypertension in the Netherlands. BMC public health. 2007 Dec;7(1):118. [DOI:10.1186/1471-2458-7-118] [PMID] [PMCID]

28. Van den Berg AE, Maas J, Verheij RA, Groenewegen PP. Green space as a buffer between stressful life events and health. Social science \& medicine. $2010 \mathrm{Apr}$ 
$1 ; 70(8): 1203-10$.

[DOI:10.1016/i.socscimed.2010.01.002] [PMID]

29. Groenewegen PP, Van den Berg AE, De Vries S, Verheij RA. Vitamin G: effects of green space on health, well-being, and social safety. BMC public health. 2006 Dec;6(1):149. [DOI:10.1186/1471-24586-149] [PMID] [PMCID]

30. Lafortezza R, Carrus G, Sanesi G, Davies C. Benefits and well-being perceived by people visiting green spaces in periods of heat stress. Urban Forestry \& Urban Greening. 2009 Jan 1;8(2):97-108. [DOI:10.1016/j.ufug.2009.02.003]

31. Laumann K, Gärling T, Stormark KM. Selective attention and heart rate responses to natural and urban environments. Journal of environmental psychology. 2003 Jun 1;23(2):125-34. [DOI:10.1016/S02724944(02)00110-X]

32. Sahlin E, Ahlborg G, Matuszczyk JV, Grahn P. Naturebased stress management course for individuals at risk of adverse health effects from work-related stresseffects on stress related symptoms, workability and sick leave. International journal of environmental research and public health. 2014 Jun;11(6):6586-611. [DOI:10.3390/ijerph110606586] [PMID] [PMCID]

33. Cervinka R, Röderer K, Hefler E. Are nature lovers happy? On various indicators of well-being and connectedness with nature. Journal of health psychology. $2012 \quad$ Apr;17(3):379-88. [DOI:10.1177/1359105311416873] [PMID]

34. Howell AJ, Dopko RL, Passmore HA, Buro K. Nature connectedness: Associations with well-being and mindfulness. Personality and individual differences. 2011 Jul 1;51(2):166-71. [DOI:10.1016/i.paid.2011.03.037]

35. Martyn P, Brymer E. The relationship between nature relatedness and anxiety. Journal of health psychology. 2016 Jul;21(7):1436-45. [DOI:10.1177/1359105314555169] [PMID]

36. Kamitsis I, Francis AJ. Spirituality mediates the relationship between engagement with nature and psychological wellbeing. Journal of Environmental Psychology. $2013 \quad$ Dec 1;36:136-43. [DOI:10.1016/j.jenvp.2013.07.013]

37. Miyazaki Y, Lee J, Park BJ, Tsunetsugu Y, Matsunaga K. Preventive medical effects of nature therapy. Nihon eiseigaku zasshi. Japanese journal of hygiene. 2011 Sep;66(4):651-6. [DOI:10.1265/ijh.66.651] [PMID]

38. Ottosson J, Grahn P. A comparison of leisure time spent in a garden with leisure time spent indoors: On measures of restoration in residents in geriatric care. Landscape research. 2005 Jan 1;30(1):23-55. [DOI:10.1080/0142639042000324758]

39. Reddy SM, Chakrabarti D, Karmakar S. Emotion and interior space design: an ergonomic perspective. Work. 2012 Jan 1;41(Supplement 1):1072-8. [DOI:10.3233/WOR-2012-0284-1072] [PMID]
40. Augustin S, Frankel N, Coleman C. Place advantage: Applied psychology for interior architecture. John Wiley \& Sons; 2009 Apr 6.

41. Schatz SL, Bowers CA. 10 Questions on Room Color: Answers for Workplace Designers. Ergonomics in Design. $2005 \quad$ Oct;13(4):21-7. [DOI:10.1177/106480460501300406]

42. Elliot AJ, Aarts H. Perception of the color red enhances the force and velocity of motor output. Emotion. 2011 Apr;11(2):445. [DOI:10.1037/a0022599] [PMID]

43. Kellert SR, Heerwagen J, Mador M. Biophilic design: the theory, science and practice of bringing buildings to life. John Wiley \& Sons; 2011 Sep 26.

44. Claudio L. Planting healthier indoor air. Environmental health perspectives. 2011;119(10):a426. [DOI:10.1289/ehp.119-a426] [PMCID]

45. Stranks JW. Human factors and behavioural safety. Routledge; 2007. [DOI:10.4324/9780080489001] [PMID]

46. Kaplan S. The restorative benefits of nature: Toward an integrative framework. Journal of environmental psychology. $\quad 1995 \quad$ Sep $1 ; 15(3): 169-82$. [DOI:10.1016/0272-4944(95)90001-2]

47. Freeman K. Nature-inspired interior landscaping: How to promote well-beingin buildings by using the principles of biophilia in interior landscape design. Retrieved February 27, 2015, from http://wwwambiuscouk/ aboutambius/biophilia/biophiliapdf. 2011.

48. Wang Y, Bakker F, De Groot R, Wörtche H. Effect of ecosystem services provided by urban green infrastructure on indoor environment: A literature review. Building and environment. 2014 Jul 1;77:88100. [DOI:10.1016/i.buildenv.2014.03.021] 